\title{
Mothball ingestion as a manifestation of pica, leading to paradichlorobenzene CNS toxicity
}

\author{
Joon Yau Leong ${ }^{1}$, Margarita Gianniosis ${ }^{2}$, Saman Zafar ${ }^{3}$, Yan Zhang ${ }^{4}$
}

1. Department of Urology, Sidney Kimmel Medical College, Thomas Jefferson University, Philadelphia PA, USA.

2. Department of Internal Medicine, Lankenau Medical Center, Wynnewood, PA, USA.

3. Department of Neurology, NewYork-Presbyterian/Weill Cornell Medical Center, New York NY, USA.

4. Department of Neurology, Albert Einstein Medical Center, Philadelphia PA, USA.

\begin{abstract}
Background: Pica is a poorly understood psychiatric disorder that presents with the ingestion of non-nutritious substances for unclear reasons. A high index of suspicion for unusual toxin exposure aids in the diagnosis of pica patients presenting with unexplained neurodegenerative features.

Methods: We present a 47-year-old female with worsening gait over the past year. Prior to this, she was fully independent with activities of daily living, but is now mostly housebound due to frequent falls. Past medical history is significant for menorrhagia, iron deficiency anemia and pica. $\mathrm{CBC}$ and iron studies revealed iron deficiency with microcytic hypochromic anemia. MRI brain demonstrated symmetrical T2 hyperintensities within the middle cerebellar peduncles.

Results: Differential diagnoses for her clinical deficits and imaging, including Spinocerebellar Ataxia, Multiple System Atrophy and Fragile X Tremor-Ataxia Syndrome, were excluded based on neurological assessment, family history and genetic PCR testing. Collateral history revealed a regular habit of mothball ingestion and serum paradichlorobenzene levels were elevated to $15 \mathrm{mcg} / \mathrm{mL}$. The patient was treated with iron replacement therapy and her symptoms gradually improved over several months.

Conclusion: Iron deficiency anemia is commonly associated with pica, which can lead to toxin ingestion. A high index of suspicion for toxin ingestion in pica patients can immensely aid in the diagnosis. Mothball abuse secondary to pica may affect the CNS and can present with nonspecific neurodegenerative changes. To our knowledge, there have been no reported cases in the literature with paradichlorobenzene neurotoxicity predominantly affecting the middle cerebellar peduncles.
\end{abstract}

Keywords: Mothball; paradichlorobenzene; PDCB; toxicity; pica; middle cerebellar peduncles.

DOI: https://doi.org/10.4314/ahs.v20i2.48

Cite as: Leong JY, Gianniosis M, Zafar S, Zhang Y. Mothball ingestion as a manifestation of pica, leading to paradichlorobenzene CNS toxicity. Afri Health Sci. 2020; 20(2): 932-935. bttps:// doi.org/10.4314/abs.v20i2.48

\section{Introduction}

Pica, the persistent ingestion of non-nutritious substances, is a poorly understood psychiatric disorder that is commonly associated with iron deficiency anemia. ${ }^{1}$
Corresponding author:
Joon Yau Leong,
Department of Urology,
Sidney Kimmel Medical College,
Thomas Jefferson University,
1025 Walnut Street, Suite 100
Philadelphia, PA 19107, USA
Phone: +1-215-955-6961
Fax: +1-215-923-1884
Email: joonyau.leong@jefferson.edu

Although uncommon, case reports of mothball ingestion secondary to pica, leading to central nervous system (CNS) toxicity, are increasingly available in the literature. Herein, we present a case of paradichlorobenzene (PDCB) neurotoxicity secondary to mothball exposure which predominantly affected the patient's middle cerebellar peduncles (MCPs).

\section{Case report}

A 47-year-old female presented with recurrent falls over the past year. A year prior to this, she was fully independent with activities of daily living, but is now wheelchair-bound due to unsteady gait and frequent falls. Past medical history is significant for menorrhagia, iron deficiency anemia and pica. On exam, she was noted to have an unidentifiable chemical odor. She exhibit- 
ed mild, symmetrical weakness on all four extremities, bilateral dysmetria on finger-nose testing and an ataxic gait. Initial laboratory work with complete blood count (CBC) revealed low hemoglobin and mean corpuscular volume at $7.8 \mathrm{~g} / \mathrm{dL}(\mathrm{N}: 12-16 \mathrm{~g} / \mathrm{dL})$ and $67.8 \mu \mathrm{m} 3(\mathrm{~N}$ : 80-100 $\mu \mathrm{m} 3)$, respectively. Her iron studies revealed ferritin levels at $7 \mathrm{ng} / \mathrm{mL}(\mathrm{N}: 40-200 \mathrm{ng} / \mathrm{mL}$ ), iron levels at $20 \mathrm{mcg} / \mathrm{dL}(\mathrm{N}: 60-150 \mathrm{mcg} / \mathrm{dL})$, total iron-binding capacity at $306 \mathrm{mcg} / \mathrm{dL}(\mathrm{N}: 300-360 \mathrm{mcg} / \mathrm{dL})$ and iron saturation at $7 \%(\mathrm{~N}: 20-50 \%)$. These findings were consistent with microcytic hypochromic anemia secondary to iron deficiency. Her brain MRI demonstrated symmetrical T2 hyperintensities within the MCPs bilaterally (Figure 1).
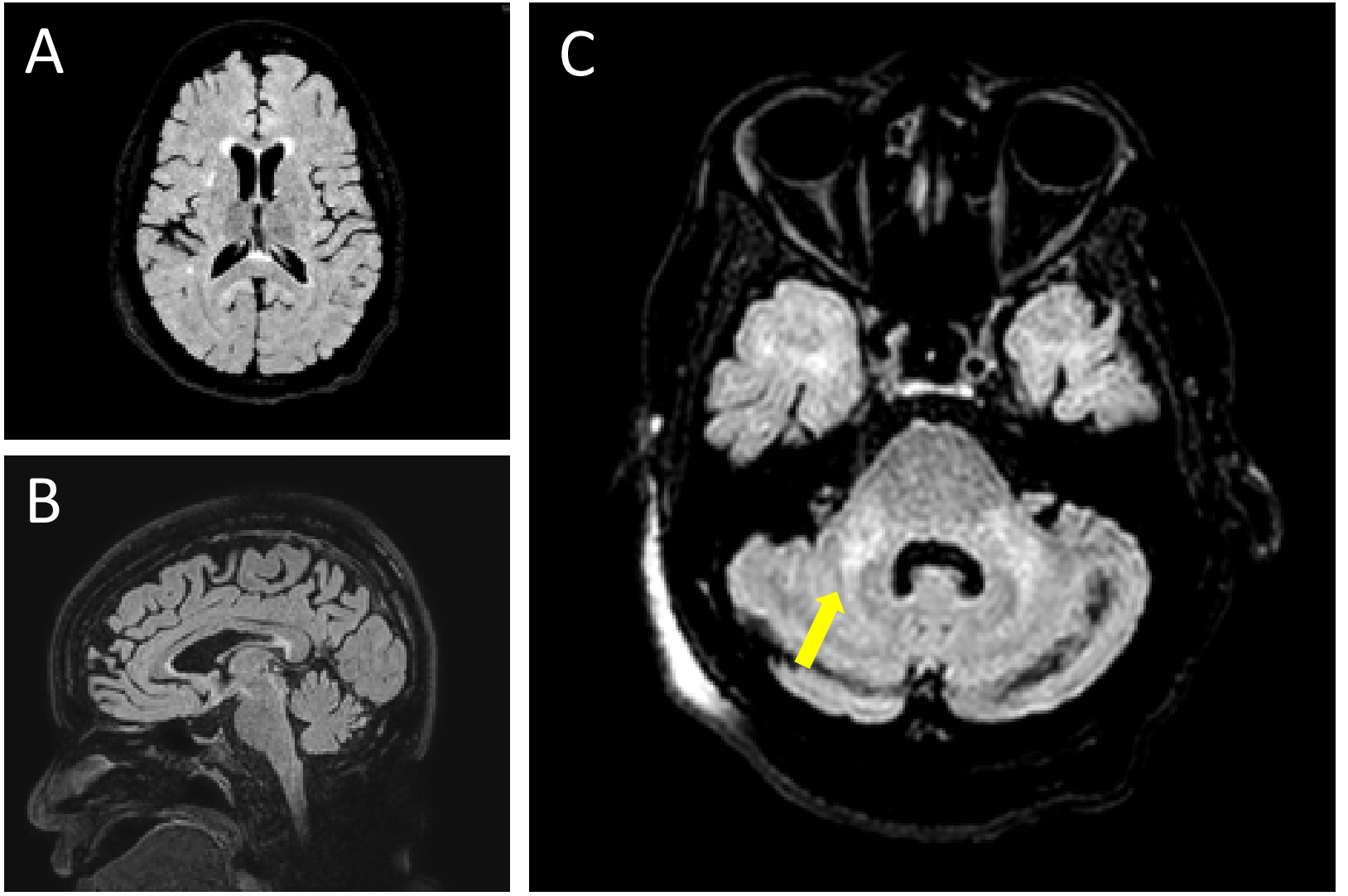

Figure 1: Brain MRI showing amorphous, relatively symmetric ill-defined regions of T2 hyperintense signals within the supratentorial white matter (A), corpus callosum (B), and bilateral middle cerebellar peduncles (C) without mass effect. There was no restricted diffusion or enhancement on other sequences. Hyperintensities affecting the middle cerebellar peduncles (arrow) were the most prominent findings on this patient's MRI.

Based on her clinical deficits and MRI findings affecting predominantly her MCPs, some differential diagnoses were deliberated. First, spinocerebellar ataxia was considered. However, this possibility was ruled out as the patient lacked the classical findings of atrophy on the pons and cerebellum on brain imaging. ${ }^{2}$ Multiple system atrophy - cerebellar type was also ruled out as patient lacked the features of autonomic dysfunction and parkinsonism. ${ }^{3}$ Next, Fragile X-associated tremor/ ataxia syndrome, although more common in men, was also considered. ${ }^{4}$ However, this was ruledut as female carriers often presents with infertility and premature ovarian failure, which was not the case in our patient who bore four children. Moreover, her genetic Fragile $\mathrm{X}$ PCR test was negative. Other potential diagnoses including bilateral anterior inferior cerebellar artery infarction and hypoglycemic coma were excluded based on the lack of risk factors, signs and symptoms and laboratory findings.

After ruling out these possibilities, collateral history from a family member revealed that the patient has been ingesting mothballs daily for the past 5 years, with the quantity increasing from $1 /$ day to $6 /$ day over the past year. The patient stated that she was "addicted to the smell" but denied feelings of euphoria or hallucinations after mothball consumption. She was also noted to have white chalky material caked between her teeth and continued to smell of mothballs throughout her four-day admission. Serum PDCB levels were drawn within the same admission and found to be elevated 
at $15 \mathrm{mcg} / \mathrm{mL}$, which is consistent with previously reported cases of PDCB toxicity. Her iron deficiency anemia was treated with iron replacement therapy and she was discharged on oral iron supplements. She was also urged to cease consumption of mothballs and any potential non-nutritious substances. Over the course of several months, her iron deficiency anemia and presenting symptoms improved and she has returned to her usual state of health.

\section{Discussion}

As PDCB is considered less toxic, it has largely replaced naphthalene as the primary component in mothballs. ${ }^{5}$
Due to its lipophilic nature, the greatest concentration of PDCB is found in adipose tissue (Figure 2). When toxin levels exceed the body's ability to store it, PDCB eventually accumulates within the CNS, which leads to demyelination and leukoencephalopathy and subsequently presents with the associated clinical symptoms. ${ }^{6}$ To date, there is no known treatment or antidotes for PDCB toxicity, although strategies including ketogenic diets and hemodialysis have been described. ${ }^{7}$ As the excretion of PDCB is primarily mediated by the kidneys, the goal of intervention for patients suffering from PDCB toxicity should be supportive care and reduction of toxin exposure, while the body gradually excretes the toxins through the urine. ${ }^{5}$

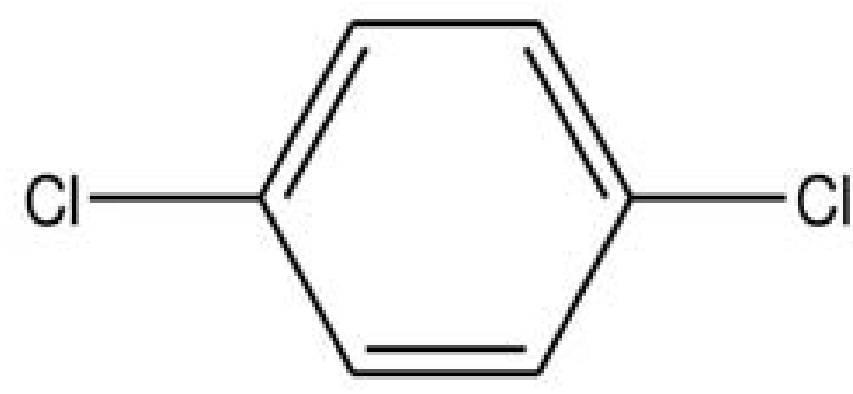

\section{1,4-dichlorobenzene}

Figure 2: Molecular structure of 1,4-para-dichlorobenzene (PDCB). The aromatic structure of the benzene ring accounts for its relatively stable properties and poor water solubility.

According to the literature, neuroimaging findings of PDCB toxicity are nonspecific and variable, ranging from the absence of MRI findings to rapidly progressive diffuse leukoencephalopathy. Multiple case reports have documented diffuse bilateral white matter changes in the brain. ${ }^{8}$ These include involvement of the supraventricular and periventricular white matter, internal capsule, splenium of the corpus callosum, cerebellum and even the brainstem. ${ }^{9}$ While most lesions exhibit hyperintensity on T2 imaging, some cases also report associated restricted diffusion on MRI which is thought to be secondary to intramyelinic edema, endothelial damage or direct toxic demyelination. ${ }^{5}$

This case was educational to us in several respects as it highlights the following general principles. First, iron deficiency anemia is commonly associated with pica, and this can lead to toxin ingestion. Seeking out a history of unusual ingestions in a patient with pica can be immensely helpful in diagnosis. Moreover, treating the underlying cause of iron deficiency anemia may also aid in resolving pica symptoms. Second, toxic-metabolic insults to the CNS secondary to environmental factors generally lead to bilateral and symmetrical changes on diagnostic imaging, as opposed to vascular or neoplastic etiologies. To our knowledge, this may also be the first reported case of PDCB toxicity predominantly affecting the MCPs. Lastly, mothball ingestion may be a manifestation of pica, which can present with nonspecific neurological findings such as cognitive deficits and ataxia.

\section{Funding Source/Grant \\ None.}




\section{Author contributions}

1) JYL, MG: Design and conceptualization, Writing (Original, Review \& Editing)

2) SZ, YZ: Resources and Supervision, Writing (Review \& Editing)

\section{Acknowledgements}

None.

\section{Conflict of interest disclosure}

All authors declare that there are no conflicts of interest.

\section{Consent}

Written informed consent was obtained from the patient for publication of this case report and accompanying images. A copy of the written consent is available for review by the Editor-in-Chief of this journal.

\section{References}

1. Khan Y, Tisman G. Pica in iron deficiency: a case series. J. Med. Case Reports. 2010;4:86.

2. Okamoto K, Tokiguchi S, Furusawa T, et al. MR features of diseases involving bilateral middle cerebellar peduncles. AJNR Am. J. Neuroradiol. 2003;24(10):19461954.
3. Savoiardo M, Strada L, Girotti F, et al. Olivopontocerebellar atrophy: MR diagnosis and relationship to multisystem atrophy. Radiology. 1990;174(3 Pt 1):693696.

4. Scaglione C, Ginestroni A, Vella A, et al. MRI and SPECT of midbrain and striatal degeneration in fragile X-associated tremor/ataxia syndrome. J. Neurol. 2008;255(1):144-146.

5. Dubey D, Sharma VD, Pass SE, Sawhney A, Stüve O. Para-dichlorobenzene toxicity - a review of potential neurotoxic manifestations. Ther. Adv. Neurol. Disord. 2014;7(3):177-187.

6. Avila E, Schraeder P, Belliappa A, Faro S. Pica with paradichlorobenzene mothball ingestion associated with toxic leukoencephalopathy. J. Neuroimaging. 2006;16(1):78-81.

7. Polman CH, Reingold SC, Banwell B, et al. Diagnostic criteria for multiple sclerosis: 2010 revisions to the McDonald criteria. Ann. Neurol. 2011;69(2):292-302.

8. Weidman EK, Tsiouris AJ, Heier LA. Toxic encephalopathy due to paradichlorobenzene toxicity: a case report and review of imaging characteristics. Clin. Imaging. 2015;39(6):1095-1098.

9. Cheong R, Wilson RK, Cortese ICM, Newman-Toker DE. Mothball withdrawal encephalopathy: case report and review of paradichlorobenzene neurotoxicity. Subst. Abus. 2006;27(4):63-67. 